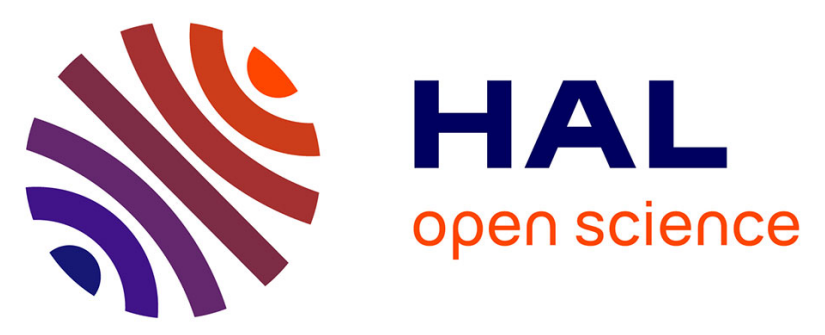

\title{
Clinical practice guidelines from the French College of Gynecologists and Obstetricians (CNGOF): benign breast tumors-Short Text
}

Vincent Lavoué, Xavier Fritel, Martine Antoine, Françoise Beltjens, Sofiane Bendifallah, Martine Boisserie-Lacroix, Loïc Boulanger, Geoffroy Canlorbe, Sophie Catteau-Jonard, Nathalie Chabbert-Buffet, et al.

\section{To cite this version:}

Vincent Lavoué, Xavier Fritel, Martine Antoine, Françoise Beltjens, Sofiane Bendifallah, et al.. Clinical practice guidelines from the French College of Gynecologists and Obstetricians (CNGOF): benign breast tumors-Short Text. European Journal of Obstetrics \& Gynecology and Reproductive Biology, 2016, 200, pp.16-23. 10.1016/j.ejogrb.2016.02.017 . hal-01282343

HAL Id: hal-01282343

https://hal-univ-rennes1.archives-ouvertes.fr/hal-01282343

Submitted on 10 Mar 2016

HAL is a multi-disciplinary open access archive for the deposit and dissemination of scientific research documents, whether they are published or not. The documents may come from teaching and research institutions in France or abroad, or from public or private research centers.
L'archive ouverte pluridisciplinaire HAL, est destinée au dépôt et à la diffusion de documents scientifiques de niveau recherche, publiés ou non, émanant des établissements d'enseignement et de recherche français ou étrangers, des laboratoires publics ou privés. 
Clinical practice guidelines from the French College of Gynecologists and Obstetricians (CNGOF): Benign breast tumors - Short Text

Vincent Lavoué ${ }^{1}$, Xavier Fritel ${ }^{2}$, Martine Antoine ${ }^{3}$, Françoise Beltjens ${ }^{5}$, Sofiane Bendifallah ${ }^{6}$, Martine Boisserie-Lacroix ${ }^{7}$, Loic Boulanger ${ }^{8}$, Geoffroy Canlorbe $^{9}$, Sophie Catteau-Jonard ${ }^{18,}$ Nathalie Chabbert-Buffet ${ }^{10}$, Foucauld Chamming's ${ }^{11}$, Elisabeth Chéreau ${ }^{12}$, Jocelyne Chopier $^{13}$, Charles Coutant ${ }^{14}$, Julie Demetz ${ }^{15}$, Nicolas Guilhen ${ }^{16}$, Raffaele Fauvet ${ }^{17}$, Olivier Kerdraon $^{19}$, Enora $\operatorname{Laas}^{20}$, Guillaume Legendre ${ }^{21}$, Carole Mathelin ${ }^{22}$, Cédric Nadeau ${ }^{23}$, Isabelle Thomassin Naggara ${ }^{24}$, Charlotte $\mathrm{Ngô}^{25}$, Lobna Ouldamer ${ }^{26}$, Arash Rafii ${ }^{27}$, MarieNoelle Roedlich ${ }^{28}$, Jérémy Seror ${ }^{29}$, Jean-Yves Séror $^{30}$, Cyril Touboul ${ }^{31}$, Catherine Uzan ${ }^{32}$, Emile Daraï ${ }^{9}$, on behalf of the French College of Gynecologists and Obstetricians (CNGOF)

1, Department of Gynecology, Rennes University hospital, France; ER440, Oncogenesis, Stress and Signaling, INSERM labeled, CRLCC Eugène Marquis, Rennes, France; University of Rennes 1, France.

2, University of Poitiers, CIC 1402, Poitiers University hospital, Poitiers. CESP Inserm U1018, Kremlin-Bicêtre, France.

3, Department of Anatomical Pathology, Hôpital Tenon, 4 rue de la Chine, 75020 Paris, France.

4, Department of Gynecology, Obstetrics and Reproductive Medicine, Hôpital Tenon, APHP, 4 rue de la Chine, 75020 PARIS, France. Inserm UMRS938.

5, Department of Anatomical Pathology, Centre Régional de Lutte contre le cancer GeorgesFrançois Leclerc, Dijon, France.

6, Department of Gynecology, Obstetrics and Reproductive Medicine, Hôpital Tenon, APHP, 4 rue de la Chine, 75020 PARIS, France. INSERM UMRS707.

7, Department of Radiology, Centre Régional de Lutte Contre le Cancer Bergognié, Bordeaux, France.

8, Department of Gynecology and Obstetrics, Hôpital Jeanne de Flandre, Lille, France.

9, Department of Gynecology, Obstetrics and Reproductive Medicine, Hôpital Tenon, APHP, 4 rue de la Chine, 75020 PARIS, France. Inserm UMRS938.

10, Department of Gynecology, Obstetrics and Reproductive Medicine, Hôpital Tenon, APHP, 4 rue de la Chine, 75020 PARIS, France.

11, Department of Radiology, Hôpital Européen Georges Pompidou, AP-HP, 15, rue Leblanc, 75015 Paris, France. 
12, Department of Surgery, Centre régional de lutte contre le cancer Paoli Calmettes, Marseille, France.

13, Department of Radiology, Hôpital Tenon, AP-HP, 4 rue de la Chine, 75020 PARIS, France.

14, Department of Surgery, Centre Régional de Lutte contre le cancer Georges-François Leclerc, Dijon, France.

15, Department of Gynecology and Obstetrics, Hôpital Jeanne de Flandre, Lille, France.

16, Department of Gynecology and Obstetrics, Poitiers University hospital, 2 rue de la Milétrie, BP 577, 86021 Poitiers Cedex, France.

17, Department of Gynecology and Obstetrics, Caen University hospital, Avenue de la Côte de Nacre 14033 Caen Cedex 09, France. University of Caen Normandy. INSERM U1199. BIOTICLA.

18, Department of Endocrine Gynecology, Hopital Jeanne de Flandre, Lille, France.

19, Department of Anatomical Pathology, Hopital Jeanne de Flandre, Lille, France.

20, Department of Gynecology, Obstetrics and Reproductive Medicine, Hôpital Tenon, APHP, 4 rue de la Chine, 75020 PARIS, France.

21, Department of Gynecology and Obstetrics, Angers University hospital, France. CESP INSERM U1018.

22, Mastology unit, CHRU Strasbourg, Hôpital de Hautepierre, Avenue Molière 67200 Strasbourg. France.

23, Department of Gynecology and Obstetrics, Poitiers University hospital, 2 rue de la Milétrie, BP 577, 86021 Poitiers Cedex, France.

24, Department of Radiology, Hôpital Tenon, AP-HP, 4 rue de la Chine, 75020 PARIS, France.

25, Department of oncological, gynecological and breast surgery, Hôpital Européen Georges Pompidou, AP-HP, 15, rue Leblanc, 75015 Paris, France. Paris-Descartes University, Paris, France.

26, Department of Gynecology, Tours University hospital. Hôpital Bretonneau. 2 boulevard Tonnellé. 37044 Tours. France. Faculty of Medicine François-Rabelais, 37044 Tours. France. Unité INSERM 1069, 37044 Tours. France.

27, Department of Obstetric Gynecology, Montpellier University hospital, France.

28, Department of Radiology, Hôpital Hautepierre, 1 av Molière, 67100 Strasbourg, France. 
29, Medical practice, 146 Avenue Ledru Rollin, 75011 Paris, France. Ultrasound department. AP-HP. Hôpital Tenon, 4 rue de la Chine, 75020 Paris. France.

30, Imagerie Duroc, R Boulevard du Montparnasse, 75006 Paris, France.

31, Department of Gynecology and Obstetrics, CHI 40, avenue de Verdun, 94000 Créteil, France.

32, Department of Gynecological and Breast Surgery and Oncology, AP-HP Pitié-Salpêtrière. 83, Bd de l'Hôpital. 75013 Paris, France. Pierre et Marie Curie University, Paris 6. France.

Corresponding Author: Collège National des Gynécologues et Obstétriciens Français CNGOF, 91 Bd Sébastopol, 75002 Paris, France. Tel. 0033144641 534. cngof@clubinternet.fr 


\section{Abstract}

Screening with breast ultrasound in combination with mammography is needed to investigate a clinical breast mass (Grade B), colored single-pore breast nipple discharge (Grade C), or mastitis (Grade C). The BI-RADS system is recommended for describing and classifying abnormal breast imaging findings.

For a breast abscess, a percutaneous biopsy is recommended in the case of a mass or persistent symptoms (Grade C). For mastalgia, when breast imaging is normal, no MRI or breast biopsy is recommended (Grade C). Percutaneous biopsy is recommended for a BI-RADS category 4-5 mass (Grade B). For persistent erythematous nipple or atypical eczema lesions, a nipple biopsy is recommended (Grade C). For distortion and asymmetry, a vacuum core-needle biopsy is recommended due to the risk of underestimation by simple core-needle biopsy (Grade C). For BI-RADS category 4-5 microcalcifications without any ultrasound signal, a minimum 11-G vacuum core-needle biopsy is recommended (Grade B). In the absence of microcalcifications on radiography cores additional samples are recommended (Grade B).

For atypical ductal hyperplasia, atypical lobular hyperplasia, lobular carcinoma in situ, flat epithelial atypia, radial scar and mucocele with atypia, surgical excision is commonly recommended (Grade C). Expectant management is feasible after multidisciplinary consensus. For these lesions, when excision margins are not clear, no new excision is recommended except for LCIS characterized as pleomorphic or with necrosis (Grade C). For grade 1 phyllodes tumor, surgical resection with clear margins is recommended. For grade 2 phyllodes tumor, $10 \mathrm{~mm}$ margins are recommended (Grade C). For papillary breast lesions without atypia, complete disappearance of the radiological signal is recommended (Grade C). For papillary breast lesions with atypia, complete surgical excision is recommended (Grade C).

Key words: benign breast tumor; mammogram; ultrasound; pathological examination, BI-RADS classification 


\section{Introduction}

Unlike for breast cancer, data and guidelines for the investigation and management of benign breast disorders are limited. The CNGOF (French College of Gynecologists and Obstetricians) therefore decided to establish clinical practice guidelines for benign breast tumors (BBT). Breast diseases during pregnancy or post partum were not included in these guidelines [1].

\section{Materials and Methods}

CNGOF appointed a committee tasked with selecting experts, compiling questions and summarizing recommendations. The summary of valid scientific data for each question analyzed by the experts included a level of evidence (LE), based on the quality of the data available and determined using the rating scheme developed by the HAS (French health authority) [2-4]:

- LE1-high-power randomized comparative trials or meta-analyses of randomized comparative trials;

- LE2-low-power randomized trials, well-conducted non-randomized comparative studies and cohort studies;

- LE3-case-control studies; and

- LE4-non-randomized comparative studies with substantial bias, retrospective studies, cross-sectional studies and case series.

The practice guidelines were summarized from the responses provided by the experts, and grades were attributed as follows:

- Grade A: established scientific evidence;

- Grade B: scientific presumption; and

- Grade C: based on a low level of evidence, generally LE3 or LE4.

Recommendations based on professional consensus (absence of conclusive scientific evidence) were reduced to strict minimum. The texts and guidelines, previously published in French [1, 5-20], were amended by external readers. 
Results

\section{Investigation of a non-inflammatory clinical breast mass [10]}

Clinical breast mass is defined as abnormality diagnosed by palpation and occupying a certain breast volume. There is a higher incidence during the 2 nd decade (peak between 30 and 50 years old) (LE3). Examination includes bilateral breast inspection and palpation with axillary and supraclavicular palpation (Grade C). A radiological breast examination is also required with at least breast ultrasound (Grade B). Mammography is performed according to clinical context (age, personal or family history and clinical findings).

\section{Investigation of inflammatory breast (mastitis) [11]}

The signs of mastitis are a red, warm breast, often associated with pain. Mastitis incidence is less than $1 \%$ of all breast disorders (LE3). Mastitis causes are divided into three groups: cancer, infection and non-infectious inflammation. Orange peel skin, upper outer quadrant location, personal or family history of breast cancer and age over 50 years are associated with cancer (LE4). On ultrasound, mass and suspicious lymph node are correlated with cancer diagnosis (LE3). On mammogram, increased skin thickness and/or mass are correlated with cancer (LE3), but mammogram is less specific than ultrasound for women under 30 years of age (LE3). MRI is the most sensitive examination (LE3). In the absence of cancer signs, antibiotic test can treat inflammatory breast disease (LE3). Mastitis should be investigated by ultrasound with axillary examination and mammogram (Grade C). The mammogram can be postponed in the event of pain. In the absence of suspected cancer an antibiotic test is recommended. If the antibiotic test fails, further radiological exams including MRI are needed (Grade C).

\section{Management of infectious breast abscess and non-infectious inflammatory disease} [12]

Acute infectious mastitis (breast abscess) is different from chronic mastitis, which can be infectious or non-infectious. Periareolar abscesses ( $90 \%$ of non-puerperal abscesses) are rare (1-2\% of symptomatic breast disease) and diagnosed in young women (mean age: 40 years). Smoking is associated with periareolar abscess and its recurrence (LE4). Staphylococcus aureus is most commonly responsible (32\% to $79 \%$ of cases) (LE4), and mycobacteria and anaerobic bacteria could also be implicated. Association of breast 
abscess with cancer is rare, but possible (LE4). Breast abscess with cancer is always associated with mass (LE4). When breast abscess is diagnosed, biopsy is recommended when associated with mass or persistent symptoms (Grade C). For abscesses less than 5 $\mathrm{cm}$, needle aspiration and surgery have similar recurrence rates (LE4). No evidence is available on duration of antibiotic treatment although most authors reported 7-10 days. For abscesses larger than $5 \mathrm{~cm}$, the evidence is contradictory in terms of whether surgery or aspiration should be recommended.

Idiopathic granulomatous mastitis (IGM) accounts for $0.5 \%-1.8 \%$ of all breast disease. It is diagnosed in young women (mean age 32 years) and characterized histologically by epithelioid granulomatous inflammation and giant cells in the breast parenchyma. Without another identified etiology such as Corynebacterium infection, tuberculosis or systemic disease (sarcoidosis, Wegener's granulomatosis, etc.), granulomatous mastitis is idiopathic (IGM). IGM generally presents with painful inflammatory breast mass $(55-100 \%$ of cases). Surgery produces faster decline of symptoms but does not prevent IGM recurrence (LE4). Corticosteroid treatment seems less invasive as first-line treatment (Grade $\mathrm{C}$ ).

Duct ectasia and periductal mastitis or inflammation are characterized on histology with low incidence: $1.1 \%$ of patients with breast symptoms (LE4). Risk factors include hyperprolactinemia (LE4), smoking (LE2) and bacterial infection (LE4). Symptoms are pain, nipple retraction, nipple discharge and mass near the nipple. Different treatments have been used but with poor efficiency. Antibiotics seem ineffective and surgery is complicated by infection, recurrence and nipple fistula (LE4). Without associated suspicious cancer symptoms, abstention is recommended (Grade C).

\section{Management of breast nipple discharge [9]}

Breast nipple discharge is physiological during and after pregnancy up to a year after breastfeeding.

Except during lactation or postpartum period, nipple discharge is defined as liquid excretion by one or more pores, whether spontaneous or induced, with variable colors and from one or both breasts.

Bilateral white multipore discharge could have endocrine etiology requiring prolactin blood test, or pharmacological etiology requiring medication survey. Nipple discharge described as watery, serous, yellow, pink or bloody is pathological, requiring 
cancer to be ruled out although found in 5\%-33\% of cases (LE2). Galactography is an invasive procedure that is more sensitive than mammography or ultrasound for detecting intraductal lesions, but is inadequate for distinguishing benign from malignant disease (LE4). Mammogram sensitivity for detecting cancer ranges from 10 to $68 \%$ and ultrasound from 20 to $100 \%$ (LE4). No evidence is available on sensitivity of nipple discharge cytology. For unipore, colored, breast nipple discharge, mammogram and ultrasound are recommended as first-line investigations (Grade B) (Grade C). If mammogram and ultrasound findings are inconclusive MRI is required (Grade C). When radiological signal is produced, percutaneous biopsy should be performed. When no radiological signal is produced, surgical pyramidotomy should be performed (Grade C).

\section{Investigation of breast nipple lesion [13]}

Any clinical change in the nipple such as erythematous lesions, pruritus, erosion or nipple retraction can lead to breast or nipple cancer diagnosis.

Bilateral nipple retraction is usually congenital. Acquired unilateral nipple retraction is associated with breast cancer (LE3), hence radiological workup is recommended (Grade C).

Erythematous nipple lesion has three main etiologies: eczema, Paget's disease and erosive nipple adenoma (LE4). Paget's disease is associated with in situ ductal or invasive carcinoma in $50 \%$ of cases. Clinical symptoms lack specificity in etiology (LE4). Corticosteroid therapeutic test could be performed if eczema is suspected. For persistent erythematous nipple or when there is no typical eczema lesion, nipple biopsy is recommended (Grade C). When Paget's disease is diagnosed, a radiological breast examination is recommended to screen for associated cancer (Grade C).

\section{Management of breast pain [14]}

Cumulative incidence of breast pain is around $45-70 \%$ during genital life. Mastalgia is defined as bilateral breast pain, predominantly in the upper lateral quadrant, for more than 4 days during premenstrual period, following menstrual cycle, or for several months. The majority of patients with mastalgia rate pain intensity at $>3.5$ on visual analog scale (VAS) (LE2). A VAS is recommended to assess intensity of breast pain (Grade B). A daily calendar is recommended to characterize breast pain (Grade C). For isolated breast pain with no physical abnormality, the radiological assessment is normal 
in $95 \%$ of cases with no increase in cancer compared with asymptomatic women (LE3). For mastalgia with no physical abnormality, no change in breast screening policy is recommended (Grade $\mathrm{C}$ ). Besides, if the mammogram and/or breast ultrasound findings are normal, MRI or breast biopsy is not recommended (Grade C). There is no specific follow-up for women with mastalgia (Grade C). Without clinical evidence of endocrine disease, hormonal blood test is not recommended (Grade C).

Reassurance alleviates mastalgia in 20 to $25 \%$ of women with mastalgia. Wearing supporting brassiere alleviates mastalgia in $85 \%$ of patients (LE3). Nonsteroidal antiinflammatory drug (NSAID) gel has shown efficacy in treatment of mastalgia and can therefore be used (Grade B). Levels of evidence were too low to recommend use of progestins for mastalgia.

\section{Role of BI-RADS in the management of breast imaging abnormalities}

The BI-RADS system classifies breast imaging abnormalities including masses, architectural distortion, asymmetry, microcalcifications and cysts and should be used [21-23] (Grade C). Grading on scale of 1 to 5 yields a predictive positive value (PPV) for cancer (Table 1). According to grade, specific follow-up plan or histological sampling is indicated (Table 2). However, low interobserver agreement for microcalcifications (kappa 0.31-0.36 for morphology and 0.29-0.50 for distribution) is noted [24, 25].

\section{Management of breast mass, architectural distortion and asymmetry on imaging findings [16]}

Mass is the radiological breast abnormality most frequently reported, followed by asymmetry and architectural distortion. The PPV of these three signs increases with women's age (LE2). Shape and contour are mass radiological characteristics (LE2). Fat content on mammography or MRI is specific for benign lesions (LE2). Mammogram features with highest PPV for cancer are irregular shape and spiculated margins (LE2). On ultrasound, spiculated margins, irregular shape, peripheral echogenic halo and long axis not oriented along the skin line have highest PPV for cancer (LE2). On MRI, signs correlated with cancer are, in decreasing order: limits, shape, signal strength, uniformity and ring enhancement (LE2). Non-mass enhancement on MRI has NPV of over $90 \%$ for cancer detection. Without mass enhancement, specificity of MRI for cancer diagnosis is 
only $70 \%$. It is recommended to describe shape and margins of mass in radiology report (Grade B). For breast mass characterization, MRI is not recommended as first-line screening (Grade B) (Figure 1).

Architectural distortion is defined as a focal defect of fibroglandular distribution and results in localized disruption of normal breast architecture without mass on imaging. In the absence of prior breast surgery, architectural distortion is classified at least BI-RADS 4. For asymmetry or distortion, add ultrasound to mammography is useful to detect ultrasound nodules as guidance for targeting biopsy (Figures 2 and 3 ). Percutaneous biopsy is recommended with BI-RADS category 4 or 5 masses (Grade B). For distortion and asymmetry, vacuum core-needle biopsy is recommended due to risk of underestimation on simple core-needle biopsy, particularly when no associated ultrasound nodule is evident (Grade C). In case of radiology/histology discordance, further investigations have to be discussed in multidisciplinary team meetings.

\section{Investigation of breast cysts [17]}

Breast cyst is radiologically defined as predominantly fluid-filled mass that is well-circumscribed and well-defined. It is the most common palpable lesion in women (37-90\% prevalence between age of 35 and menopause), (LE3). Breast cysts are classified as simple, complicated or complex.

On ultrasound, simple cyst is a pure anechogenic image with posterior enhancement, and is classified as BI-RADS 2 (100\% NPV for detection of cancer) (LE3). No further investigation is recommended for simple cysts (Grade C). Cytology is not recommended (Grade $\mathrm{C}$ ) because they are always benign (LE3).

On ultrasound, complicated cyst is similar to simple cyst but with finely echogenic homogeneous contents (2\% NPV for detection of cancer) (LE3) and is classified as BI-RADS 3. A follow-up US examination is required every 6 months for 2 years (Grade C). For high-risk family breast cancer or BRCA mutation patients, medullary carcinoma can mimic complicated cyst prompting biopsy rather than followup. Elastography can identify subgroup of patients at risk of cancer by detecting solid lesion in cyst, thus leading to complicated cyst (BI-RADS 3) being upgraded to a complex cyst (BI-RADS 4). However, elastography is not recommended due to its high interobserver variability. Cytology may be of value for detecting complicated cysts. Cytology results are of 4 types: benign, non-contributory, atypical and malignant. In the 
case of benign cytology result for complicated cyst, follow-up assessment at 6 months is recommended (Grade C). In the case of non-contributory, atypical or malignant cytology result, percutaneous biopsy is recommended (Grade C).

A complex cyst is similar to complicated cyst but is heterogeneous with both cystic and solid components. The incidence of cancer associated with a complex cyst is between 3 and 36\% (LE3). Complex cysts are classified as BI-RADS 4, hence percutaneous biopsy is recommended (Grade C).

If the fluid is bloody on cyst puncture cytology review is recommended (Grade C).

Mammography and tomosynthesis are of no use for investigating ultrasound cystic breast syndrome. There are no available data on the contribution of MRI for cystic lesions.

\section{Investigation of breast microcalcifications [15]}

A breast microcalcification is defined as calcium deposit of less than $1 \mathrm{~mm}$ seen on mammogram. Microcalcification cluster is defined as at least 5 microcalcifications within an area of $1 \mathrm{~cm}^{2}$. Microcalcification clusters are most often benign but can be malignant. In women with BI-RADS 4 or 5 microcalcifications, ultrasound can be used to achieve targeted biopsy, detect signs of cancer or for other diagnoses. For BI-RADS 4 or 5 microcalcifications percutaneous biopsy is recommended (Grade B). Data on tomosynthesis for microcalcifications either alone or in combination with 2D mammography are contradictory. Given the insufficient data on elastography for microcalcifications no recommendations may be made. MRI has a poor sensitivity and NPV for the detection and characterization of microcalcifications (LE2). The use of MRI to characterize mammographically detected microcalcifications is not recommended (Grade B). For BI-RADS 4 or 5 microcalcifications with no ultrasound signal, minimum 11-G vacuum core-needle biopsy is recommended (Grade B). In the absence of microcalcifications within radiograph cores, additional sampling is recommended (Grade B) (Figures 4 and 5).

\section{Management of breast epithelial proliferation with or without atypia [18]}

Atypical ductal hyperplasia (ADH), flat epithelial atypia (FEA), atypical lobular hyperplasia (ALH) and lobular carcinoma in situ (LCIS) are proliferations of 
monomorphic epithelial cells in the terminal ductal-lobular unit as defined by the histological criteria of the 2012 WHO classification.

For ADH diagnosed from percutaneous biopsy, rate of underestimation (i.e. finding invasive breast carcinoma or ductal carcinoma in situ) varies from 13 to $21 \%$ (LE3). Predictors of underestimation are 14-G instead of 9-11G biopsy, BI-RADS category 4-5 versus 3, architectural distortion, clinically symptomatic lesion, mass, ultrasound signal, radiological size $>15 \mathrm{~mm}$, persistence of post-biopsy radiological signal (residual calcifications), multiple foci $\geq 3$, marked cytonuclear atypia and less experienced pathologist (LE3).

For percutaneous biopsy FEA diagnosis, the underestimation rate is between 0 and $20 \%$ (LE4). In the case of vacuum core-needle biopsy ALH or LCIS diagnosis, the underestimation rate varies between $3 \%$ and $17 \%$, modulated by radiology/histology concordance (LE3). In the case of non-conventional LCIS, the underestimation rate is around $50 \%$ (LE4).

For radial scars on percutaneous biopsy, the underestimation rate varies from $8.2 \%$ to $16.7 \%$ (LE3).

For a mucocele with atypia or associated with mass, the underestimation rate is between 21 and 31\% (LE3).

For atypical ductal hyperplasia, atypical lobular hyperplasia, lobular carcinoma in situ, flat epithelial atypia, radial scar or a mucocele with atypia, surgical excision is commonly recommended (Grade C). Expectant management is feasible following multidisciplinary discussion. For these lesions, when clear margins are not achieved, no further excision is recommended except for pleomorphic LCIS or LCIS with necrosis (Grade C).

For ADH, FEA, ALH, LCIS, radial scar or mucocele with atypia and/or mass diagnosed by percutaneous biopsy, surgical excision is commonly recommended (Grade C). For these lesions, in case of complete disappearance of radiological signal and for ADH, FEA, ALH, LCIS (excluding pleomorphic LCIS or LCIS with necrosis) or radial scar without atypia, expectant management is feasible following multidisciplinary consensus. In the event of incomplete surgical excision, surgical reexcision is not useful (Grade C). 
For ADH, FEA, ALH and LCIS, the risk of cancer is 4 (intermediate) (LE3) and specific follow-up is recommended in accordance with the HAS (French health authority) guidelines (Grade C) [26].

For FEA or radial scar or mucocele with atypia, there is little or no data to support different monitoring approach to that of other lesions with atypia.

No data on the risk of underestimation in event of case of simple hyperplasia (SH), sclerosing adenosis (SA) or fibrocystic changes (FC) by percutaneous biopsy are available.

For mucocele without atypia diagnosed by percutaneous biopsy the underestimation rate is under 2\% (NP4). Excisional surgery is not recommended.

$\mathrm{SH}, \mathrm{SA}, \mathrm{FC}$ and radial scar are associated with a low increased risk of breast cancer (RR of around 2 or less) (LE3), hence no specific follow-up is recommended (Grade C).

\section{Management of fibro-epithelial breast tumor [19, 20]}

Fibroadenoma (FA) is benign tumor with both conjunctival and epithelial components and an incidence of 13\% (LE4). FA is associated with an RR of cancer within 20 years of 1.7 (95\% CI 1.1 to 2.5) (LE3) and does not require specific follow-up (Grade C). For FA associated with proliferative lesions and/or atypia and/or a family history, RR of cancer within 20 years is between 3.7 (95\% CI 1.5 to 9.2) and 6.9 (95\% CI 1.5 to 30.6), respectively (LE3), requiring specific follow-up in accordance with HAS guidelines (Grade C). Without treatment, FA can remain stable, decrease or increase in $55 \%, 37 \%$ and $8 \%$ of cases, respectively (LE3). In case of percutaneous biopsy FA diagnosis, discordance between clinical, radiological and pathological findings, complex FA, proliferative lesions or atypia with FA, or a family history of cancer, it seems legitimate to discuss management in multidisciplinary team meetings. When surgery is proposed for FA, a periareolar rather than direct incision is associated with a more insensitive nipple but better cosmetic results (LE4). When surgery is proposed for FA, indirect incision is preferable for better cosmetic results (Grade C). Percutaneous destruction or resection techniques can be used (Grade C).

Phyllodes breast tumors (PBT) are rare. The WHO classification divides them into three categories: benign (Grade 1), borderline (Grade 2) and malignant (Grade 3). The PPV of percutaneous biopsy for PBT is low (52.7\%) (LE4), hence surgical excision is 
recommended. (Grade C). PBT grades 1 and 2 are respectively associated with a local recurrence risk of $15 \%$ and $17 \%$ and a distant recurrence risk of 0.1 and $0.2 \%$ (LE4).

For grade 1 PBT (mild), the risk of local recurrence after surgical excision increases when the PBT lesion is in contact with the surgical margins (not clear). After clean resection, there is no correlation between margin size and the risk of recurrence (LE4).

For grade 2 PBT, local recurrence after surgical excision increases for margins under $10 \mathrm{~mm}$ (LE4).

For grade 1-2 PBT, resection with clear margins is recommended.

For grade 2 PBT, $10 \mathrm{~mm}$ margins are recommended (Grade C). No lymph node evaluation or systematic mastectomy is recommended (Grade C).

For grade 1-2 PBT, no specific follow-up data are available.

Papillary breast lesions (PBL) show ductal epithelial proliferation around vascular connective axis. PBLs without atypia are associated with invasive or ductal carcinoma in situ underestimation rate of 0\%-29\% (LE4). PBLs with atypia are associated with an underestimation rate of 6\%-70\% (LE2). For PBLs without atypia, complete resection of the radiological target is recommended (Grade C). For PBLs with atypia, complete excisional surgery is recommended (Grade C).

After excision of PBLs, atypia or multifocality are associated with a risk of developing cancer (RR: 2.04 to 7.01) (LE3). For PBLs without atypia but with no surgical excision (single ablation biopsy), there are insufficient data to determine whether or not specific follow-up should be recommended. For PBLs with atypia, the RR of cancer is considered moderate to high (RR: 2.04 to 7.01) requiring specific follow-up in accordance with HAS guidelines (Grade C).

Abrikossoff's tumor or granular cell tumor (GCT) is a rare benign disease. The association of GCT with cancer (sometimes at a distance of $2 \mathrm{~cm}$ ) is under $2 \%$ (LE4). For GCT diagnosed by percutaneous biopsy no surgery is recommended if there is no radiology/histology discordance (Grade C). Surgery with clear margins is not required (Grade C).

Erosive adenomatosis of the nipple (EAN) accounts for $15 \%$ of all nipple tumors. The differential diagnosis is Paget's disease. Concomitant cancer is found in $12-14 \%$ of cases (LE4). After EAN surgery, recurrence is exceptional and without an excess risk of 
cancer (LE4). For EAN, surgical excision is recommended to exclude Paget's disease or cancer (Grade C).

Breast fibromatosis or desmoid tumor is a fibroblast proliferation accounting for less than $0.2 \%$ of primary breast tumors and $4 \%$ of extra-abdominal fibromatosis. For fibromatosis, there are no data to advise simple follow-up as opposed to surgery. The overall recurrence rate after excisional surgery is 18-29\% (LE4) (5-25\% after clear excision and $55-100 \%$ in cases of excision without clear margins). When surgery is performed for a desmoid tumor, negative margins are recommended (Grade C).

Breast hemangioma is a rare vascular tumor developing in the breast parenchyma or adjacent tissue under the skin (LE4). The main differential diagnosis is angiosarcoma. A palpable tumor larger than $2 \mathrm{~cm}$, a recent increase in volume, a pulsating lesion and angiomatous purplish skin are more frequently associated with hemangiosarcoma (LE4) and the need for surgical excision (Grade C). 


\section{Conflict of interest statement}

The authors declare no conflict of interest in relation to the subject of this article.

\section{Scope}

These French guidelines for the diagnosis and treatment of benign breast tumors apply to gynecologists, obstetricians, surgeons, radiologists, pathologists and general practitioners.

\section{Acknowledgments}

The authors would like to thank Ms Patricia Lemoine and Ms Chantal Capelle for their rigorous logistic organization.

The authors would also like to thank the following working group experts: Matthieu Muller, Séverine Alran, Tristan Gauthier, Jean Levêque, Corinne Bézu-Lepillier, Cyrille Huchon, Rémy Salmon, Gilles Carrasset, Yann Delpech, Jean-Luc Brun, Pascal Bigel, Gwenaelle Boivin-Le Pottier, François D’Halluin. 


\section{References}

[1] Lavoue V, Fritel X, Antoine M, Ballester M, Beltjens F, Bendifallah S, et al. Clinical practice guidelines from the French College of Gynaecologists and Obstetricians: Benign breast tumor - Aims, methods and organization. J Gynecol Obstet Biol Reprod (Paris). 2015;Epub ahaed of print.

[2] Rédaction de l'argumentaire scientifique - Elaboration de recommandations de bonne pratique et des recommandations. Fiche méthodologique de la HAS; 2010.

[3] Méthode recommandations pour la pratique clinique - Elaborations de recommandations de bonne pratique. Fiche Méthodologique de la HAS; 2010.

[4] Grille d'évaluation de la qualité des recommandations de bonne pratique (dérivée de la grille AGREE II). Fiche méthodologique de la HAS; 2011. .

[5] Darai E, Lavoue V, Fritel X. [Clinical practice guidelines: Benign breast tumor Introduction]. J Gynecol Obstet Biol Reprod (Paris). 2015;44:896-7.

[6] Lavoue V. Tumeurs bénignes du sein : recommandations pour la pratique clinique du Collège National des Gynécologues et Obstétriciens Français (CNGOF) - Texte Court. 2015.

[7] Lavoue V, Fritel X, Antoine M, Beltjens F, Bendifallah S, Boisserie-Lacroix M, et al. [Benign breast tumors: Recommendations of College National des Gynecologues Obstetriciens Francais (CNGOF) - Short text]. J Gynecol Obstet Biol Reprod (Paris). 2015;44:1049-64.

[8] Lavoue V, Fritel X, Chopier J, Roedlich MN, Chamming's F, Mathelin C, et al. [Clinical practice guidelines: Benign breast tumor - Aims, methods and organization]. J Gynecol Obstet Biol Reprod (Paris). 2015;44:898-903.

[9] Ouldamer L, Kellal I, Legendre G, Ngo C, Chopier J, Body G. [Management of breast nipple discharge: Recommendations]. J Gynecol Obstet Biol Reprod (Paris). 2015;44:927-37.

[10] Legendre G, Guilhen N, Nadeau C, Brossard A, Fauvet R. [Exploring a noninflammatory clinical breast mass: Clinical practice guidelines]. J Gynecol Obstet Biol Reprod (Paris). 2015;44:904-12.

[11] Touboul C, Laas E, Rafii A. [Exploration of breast inflammation excluding pregnancy and breastfeeding: Guidelines]. J Gynecol Obstet Biol Reprod (Paris). 2015;44:913-20.

[12] Laas E, Touboul C, Kerdraon O, Catteau-Jonard S. [Inflammatory and infectious breast mastitis outside of pregnancy and lactation: Guidelines]. J Gynecol Obstet Biol Reprod (Paris). 2015;44:996-1016.

[13] Boulanger L, Demetz J. [How to explore breast skin lesion?: Guidelines]. J Gynecol Obstet Biol Reprod (Paris). 2015;44:921-6.

[14] Ngo C, Seror J, Chabbert-Buffet N. [Breast pain: Recommendations]. J Gynecol Obstet Biol Reprod (Paris). 2015;44:938-46.

[15] Chamming's F, Chopier J, Mathelin C, Chereau E. [Explorations of breast microcalcifications: Guidelines]. J Gynecol Obstet Biol Reprod (Paris). 2015;44:960-9.

[16] Chopier J, Roedlich MN, Mathelin C. [Breast imaging of mass, architectural distortion and asymmetry: Clinical practice guidelines]. J Gynecol Obstet Biol Reprod (Paris). 2015;44:947-59.

[17] Uzan C, Seror JY, Seror J. [Management of a breast cystic syndrome: Guidelines]. J Gynecol Obstet Biol Reprod (Paris). 2015;44:970-9.

[18] Coutant C, Canlorbe G, Bendifallah S, Beltjens F. [Benign proliferative breast disease with and without atypia]. J Gynecol Obstet Biol Reprod (Paris). 2015;44:980-95. 
[19] Canlorbe G, Bendifallah S. [Rare benign breast tumors including Abrikossoff tumor (granular cell tumor), erosive adenomatosis of the nipple, cytosteatonecrosis, fibromatosis (desmoid tumor), galactocele, hamartoma, hemangioma, lipoma, juvenile papillomatosis, pseudoangiomatous hyperplasia, and syringomatous adenoma: Guidelines for clinical practice]. J Gynecol Obstet Biol Reprod (Paris). 2015;44:1030-48. [20] Bendifallah S, Canlorbe G. [Common benign breast tumors including fibroadenoma, phyllodes tumors, and papillary lesions: Guidelines]. J Gynecol Obstet Biol Reprod (Paris). 2015;44:1017-29.

[21] ACR BI-RADS Mammographie. Deuxième édition française basée sur la 4ème édition américaine, 2004. American College of Radiology (ACR). ACR-BI-RADSMammography. ACR Breast Imaging Report. Data Syst. Breast Imaging Atlas. Reston, Va.: 2003.

[22] ACR BI-RADS-IRM. Première édition française basée sur la 1ère édition américaine, 2004. American College of Radiology (ACR). ACR-BI-RADS-Magnetic Resonance Imaging. ACR Breast Imaging Report. Data Syst. Breast Imaging Atlas. Reston, Va.: 2003.

[23] ACR BI-RADS -Echographie. Première édition Française basée sur la 1ère édition américaine. American College of Radiology (ACR). ACR-BI-RADS- Ultrasound. ACR Breast Imaging Report. Data Syst. Breast Imaging Atlas. Reston, Va: 2004.

[24] Lazarus E, Mainiero MB, Schepps B, Koelliker SL, Livingston LS. BI-RADS lexicon for US and mammography: interobserver variability and positive predictive value. Radiology. 2006;239:385-91.

[25] Berg WA, Campassi C, Langenberg P, Sexton MJ. Breast Imaging Reporting and Data System: inter- and intraobserver variability in feature analysis and final assessment. AJR Am J Roentgenol. 2000;174:1769-77.

[26] Dépistage du cancer du sein en France : identification des femmes à haut risque et modalités de dépistage. HAS; 2011. . 
Figure 1: Breast imaging : benign mass characteristics
A. Fibro-adenoma
B. Fibro-adenoma (magnification)
C. Benign mass at MRI.
D. Benign mass at elastography
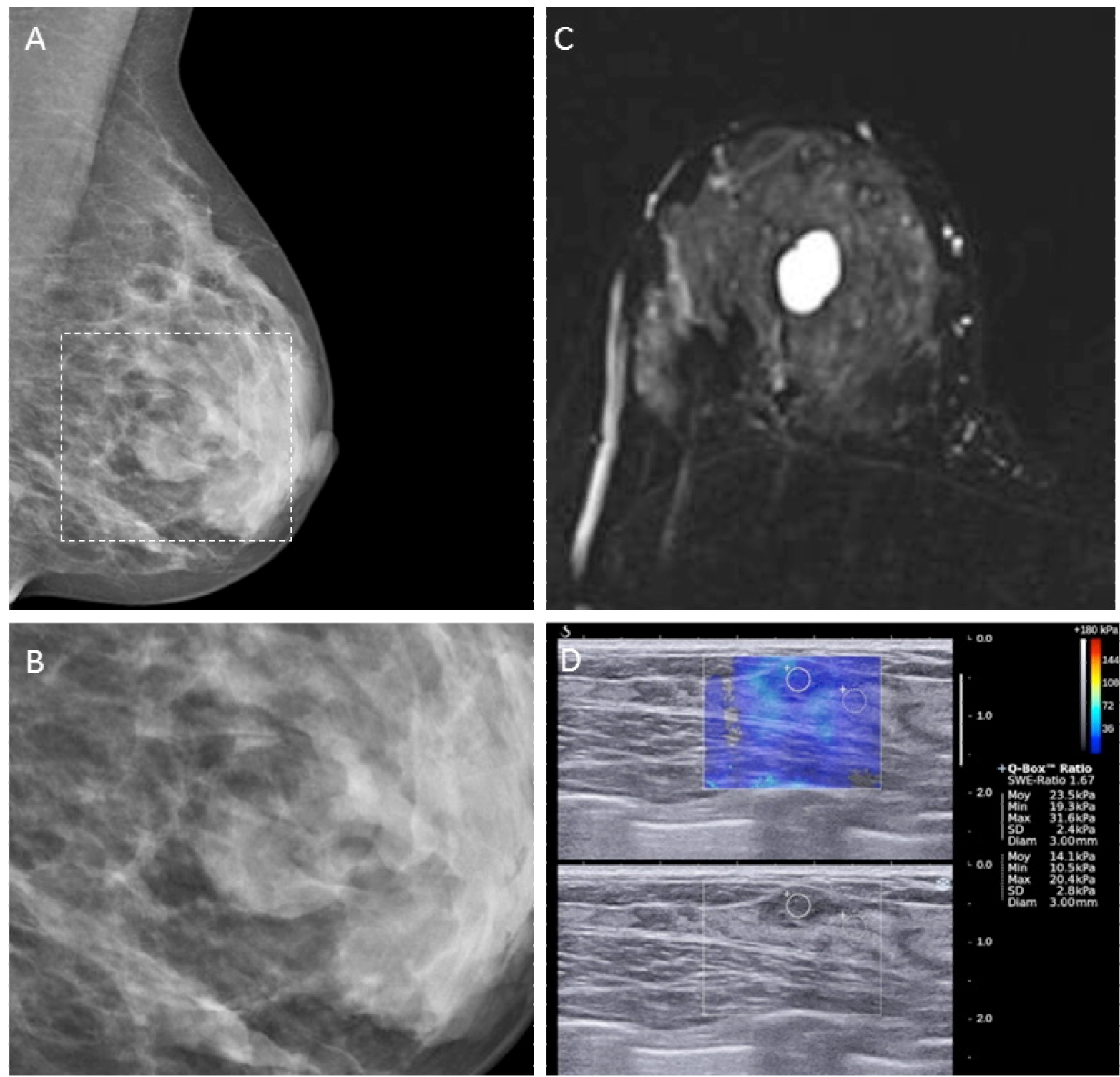
Figure 2: Breast imaging : asymmetries' characteristics
A. Simple asymmetry.
B. Global asymmetry.
C. Focal asymmetry.
D. Evolutive asymmetry

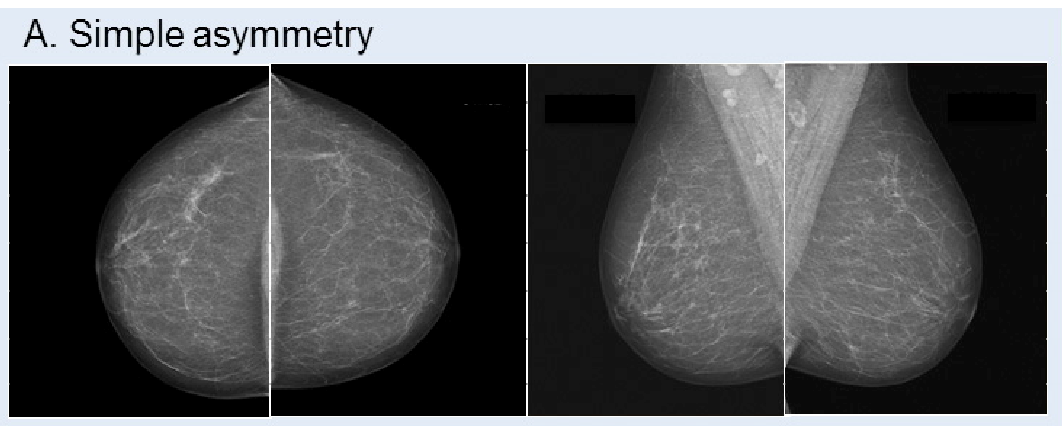

B. Global asymmetry

C. Focal asymmetry

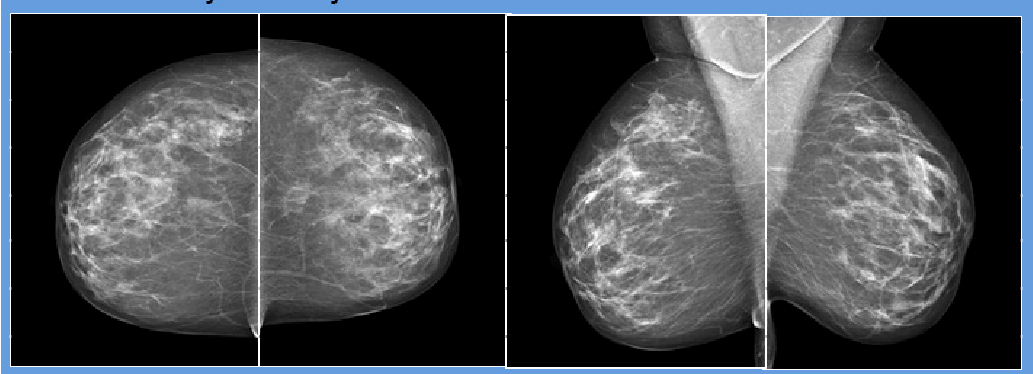

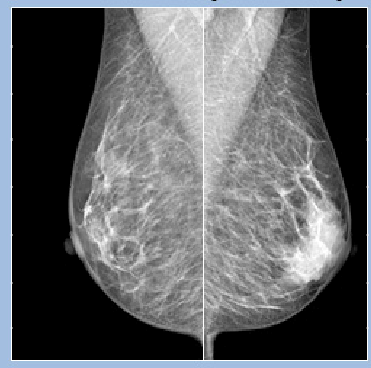

D. Developing asymmetry

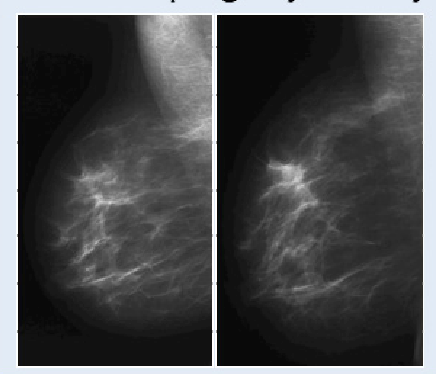


Figure 3: Breast imaging : architectural distorsions characteristics

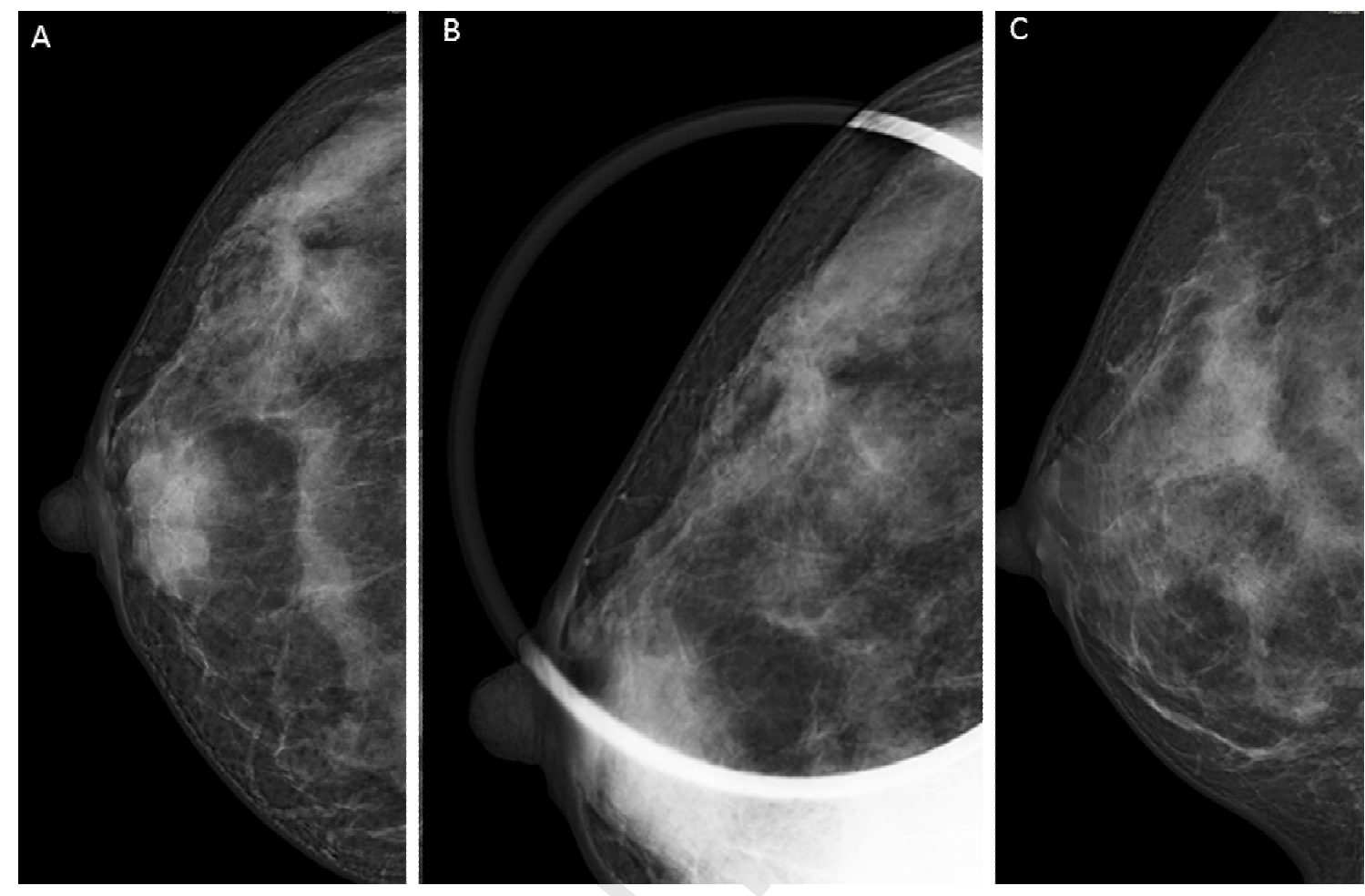


Figure 4: Morphological characteristic of benign microcalcifications

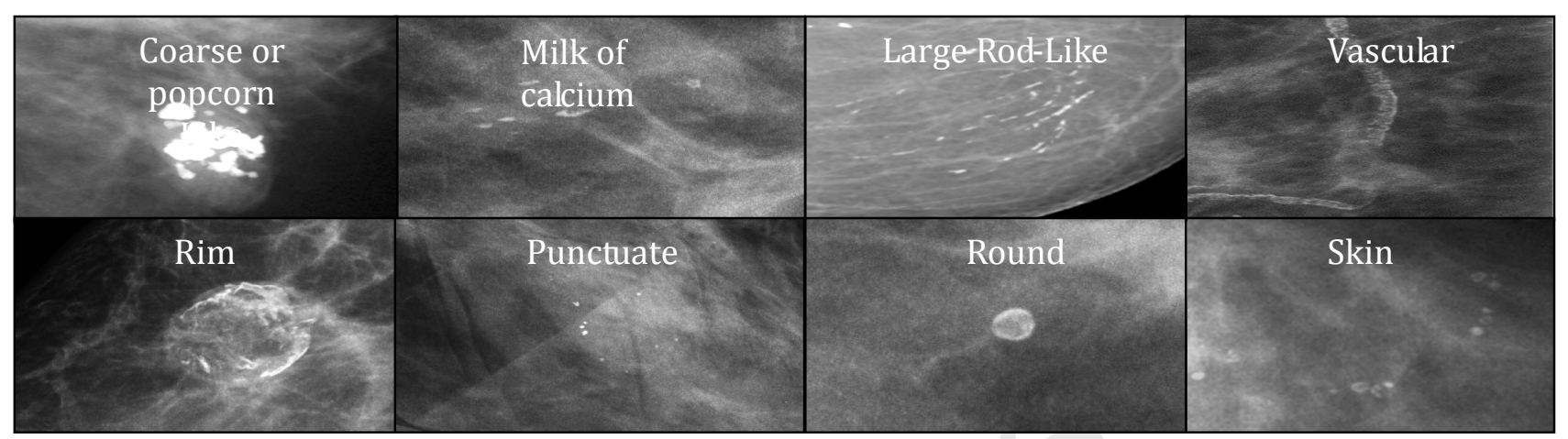


Figure 5: Morphological characteristic of suspicious microcalcifications

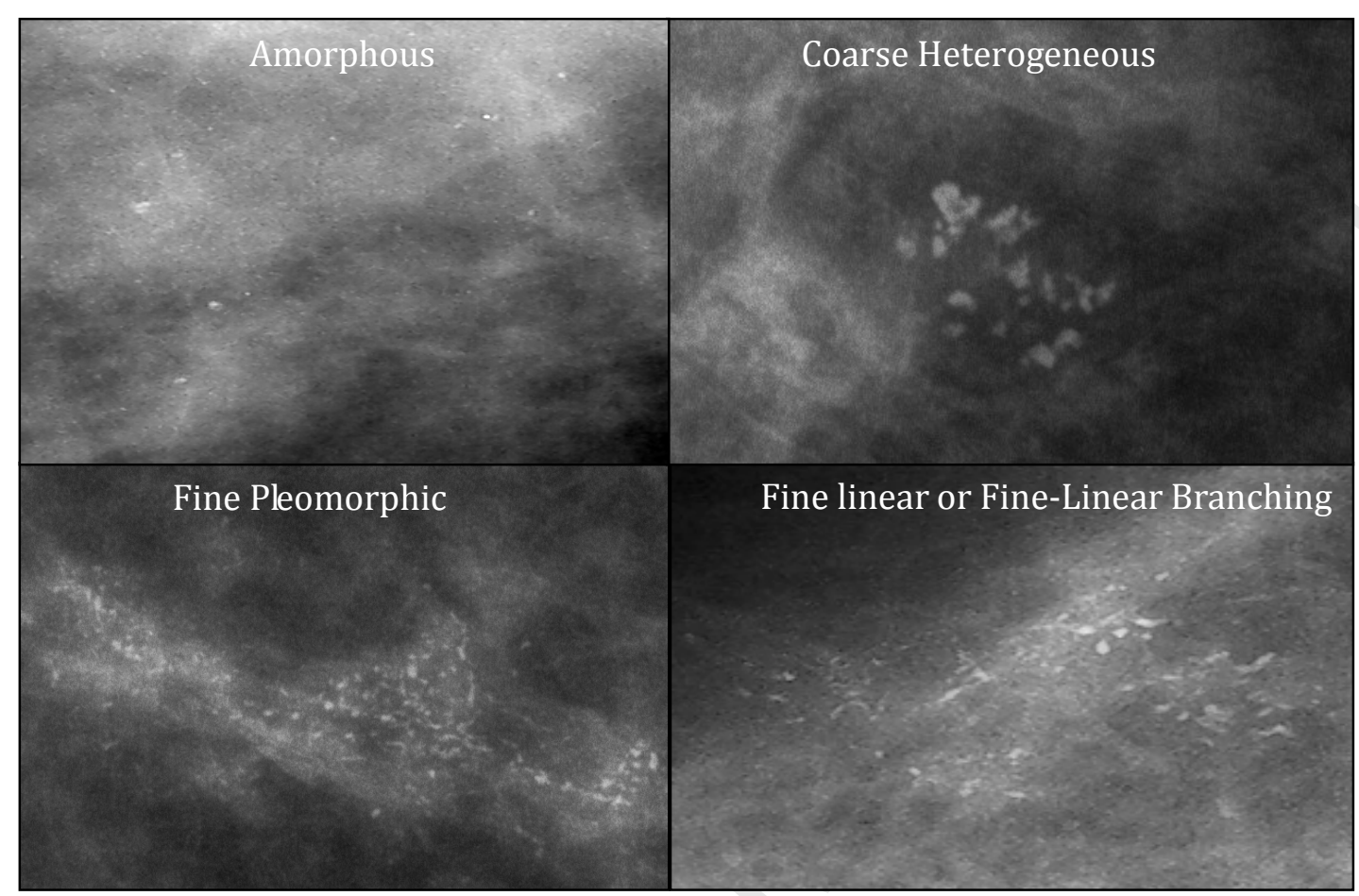


Table 1 : BI-RAD assessement categories

\begin{tabular}{lll}
\hline Categories & \multicolumn{1}{c}{ Cancer PPV* } & Bi-RADS \\
& & \\
\hline 0 & Incomplete & BI-RADS 0 \\
\hline 1 & $0 \%$ (Negative) & BI-RADS 1 \\
\hline 2 & $0 \%$ (Benign) & BI-RADS 2 \\
\hline 3 & $<2 \%$ (Probably Benign) & BI-RADS 3 \\
\hline 4 & $\geq 2$ et $<95 \%$ (Suspicious) & BI-RADS 4 \\
& $<10 \%$ (low suspicious) & BI-RADS 4A \\
& $10-50 \%$ (intermediate suspicion) & BI-RADS 4B \\
& $>50 \%$ et $<95 \%$ (moderate concern, but & BI-RADS 4C \\
& not classic for malignancy) & \\
\hline 5 & $\geq 95 \%$ (highly suggestive of malignancy) & BI-RADS 5 \\
\hline 6 & Known biopsy - proven malignancy & BI-RADS 6 \\
\hline
\end{tabular}

PPV : Positive Predictive Value 
Table 2 : Diagnosis and therapeutic implications of BI-RADS classification

\begin{tabular}{ll}
\hline & \multicolumn{1}{c}{ Therapeutic implications } \\
\hline BI-RADS 0 & Additional imaging evaluation \\
\hline BI-RADS 1 & Normal follow-up \\
\hline BI-RADS 2 & Normal follow-up \\
\hline BI-RADS 3 & Follow-up with repeat imaging \\
& $(6,12,24$ months $)$ \\
\hline BI-RADS 4 & Biopsy \\
\hline BI-RADS 5 & Biopsy \\
\hline
\end{tabular}

